\title{
Radon in Soil Gas Above Bedrock Fracture Sets at the Shepley's Hill Superfund Site
}

J. R. Giles

T. L. McLing

W. Brandon

M. V. Carpenter

C. J. Smith

December 2012

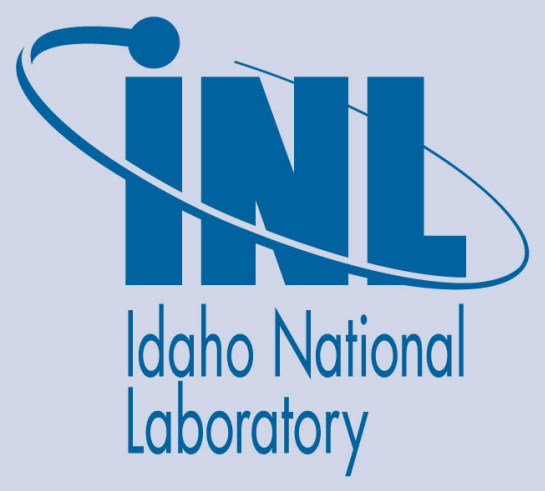

The INL is a U.S. Department of Energy National Laboratory operated by Battelle Energy Alliance 


\title{
Radon in Soil Gas Above Bedrock Fracture Sets at the Shepley's Hill Superfund Site
}

\author{
J. R. Giles \\ T. L. McLing \\ W. Brandon \\ M. V. Carpenter \\ G. J. Smith
}

December 2012

\section{Idaho National Laboratory \\ Idaho Falls, Idaho 83415}

http://www.inl.gov

Prepared for the

Environmental Protection Agency and for the

U.S. Department of Energy

Assistant Secretary for Environment, Safety, and Health

Under DOE Idaho Operations Office

Contract DE-AC07-05ID14517 


\author{
Radon in Soil Gas Above Bedrock Fracture Sets at the Shepley's Hill Superfund Site \\ J. R. Giles ${ }^{1}$, T. L. McLing ${ }^{1}$, W. Brandon ${ }^{2}$, M. V. Carpenter ${ }^{1}$, C. J. Smith ${ }^{1}$ \\ ${ }^{1}$ Idaho National Laboratory; ${ }^{2}$ U.S. EPA Region 1
}

\title{
Introduction
}

The Idaho National Laboratory (INL) recently provided technical support for ongoing environmental characterization and remediation activities at the Shepley's Hill Superfund site near Devens, MA (Figure 1). The objective of the technical assistance was to identify a methodology that can be used to identify the locations of fracture sets in near-surface bedrock. The hypothesis tested here is that areas near the ground surface that exhibit elevated concentrations of naturally occurring radioactivity (i.e. Rn-222 and its decay products) are associated with fractures in the underlying bedrock. Based on previous geological studies (Gannett Fleming, 2012), numerous bedrock fracture sets at the Shepley's Hill site have been identified which serve as conduits for contaminant transport through the bedrock groundwater system.

The recent technical support phase was requested as follow-on work to an initial screening level radiation survey conducted in 2008. The purpose of the original study was to assess the efficacy of the INL-developed Backpack Sodium lodide System (BaSIS) for detecting elevated areas of natural radioactivity due to the decay of radon-222 gas emanating from the underlying bedrock fractures. Although the results from the initial study were mixed, the BaSIS radiation surveys did confirm that exposed bedrock outcrops at the site have higher natural radioactivity than the surficial soils, and thus there is a high potential for preferentially detecting elevated levels of radon and/or radon daughter products from the natural bedrock sources. (INL 2009) It was observed that the short count times associated with the BaSIS measurements limited the ability of the system to respond to elevated levels of radioactivity from subsurface sources, in this instance radon gas emanating from buried bedrock fracture sets. Based on this previous work, it was postulated that a different methodology be employed to directly detect the radon in the soil gases. The CR-39 particle track detectors were selected through an extensive literature and technology search. The relatively long deployment or "detection" time of several days, as well as the sensitivity of the measurement and robustness of the detectors made the CR-39 technology promising for deployment toward the technical objectives at the Shepley's Hill site.

STI Number: INL/EXT-12-27844

Revision: 0 


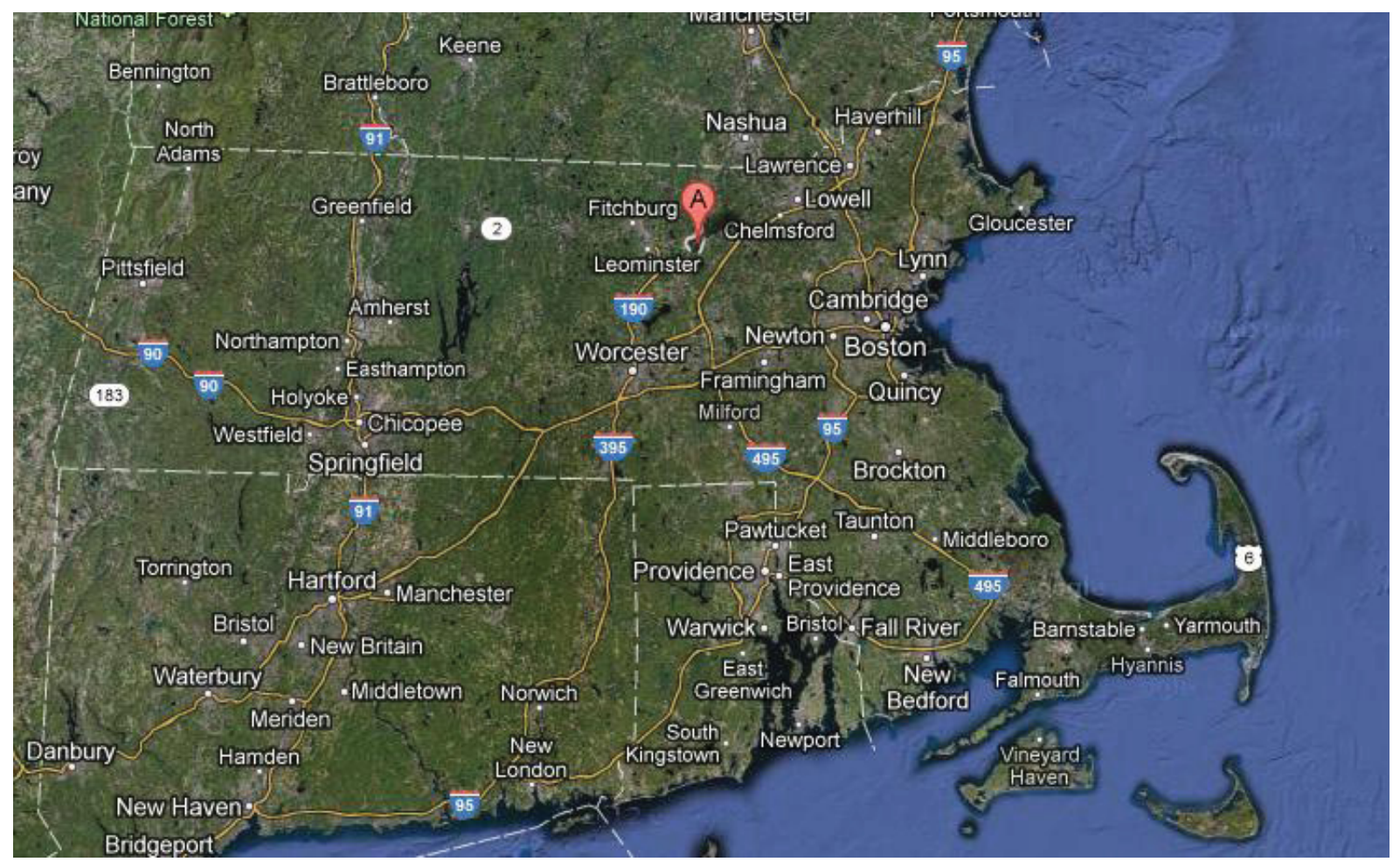

Figure 1. Location of Shepley's Hill study area.

\section{Investigation Area}

Fort Devens (partially closed in 1996) is located 35 miles west of Boston. Fort Devens formerly was comprised of approximately 9,280 acres divided into North, Main, and South Posts. The facility was located in the towns of Ayer and Shirley in Middlesex County, and Lancaster and Harvard in Worcester County. Massachusetts Highway 2 divides the South post from the Main Post. The Nashua River runs through the North, Main, and South Posts. Presently, only the South Post and a small enclave on the North Post remain as active military installations. The area surrounding the former Fort Devens is largely rural/residential. Three principal drinking water wells are located within one mile of the Shepley's Hill Landfill (on the Main Post) - the McPherson water supply well (located west of the wetlands near Nonacoicus Brook) and the Devens and Grove Pond well-fields (located on the south shore of Grove pond and upgradient of the landfill).

Camp Devens was created as a temporary cantonment in 1917 for training soldiers from the New England area. In 1932, the Camp was formally dedicated as Fort Devens and trained active duty personnel for World War II, the Korean and Vietnam wars. In July of 1991, the North and Main Posts of Fort Devens were slated for closure and the South Post for realignment under the Defense Base Realignment and Closure Act (BRAC). The installation ceased to be Fort Devens on March 31, 1996 at which time the remaining Army mission was assimilated by the Devens Reserve Forces Training Area (DRFTA). Fort Devens was listed on the National Priorities List (NPL) in November 1989. The closure of Fort Devens accelerated the investigations and cleanup to protect human health and the environment in a timely fashion and facilitate economic redevelopment. 
An area of granitic uplands at Devens located directly west of the Shepley's Hill Landfill on the former North Post was selected for this study based on the abundance of surface exposures and availability of complementary geologic data (Gannett Fleming, 2012). The proposed study is generally directed toward better understanding the nature and position of fractures in shallow bedrock given their potential for transporting contaminants in ground water and gaseous phases. Another specific goal of the study was to assess the viability of the CR-39 approach in identifying bedrock fractures in an area where other work has independently identified their locations. If successful, the technology may offer a low-cost method for locating buried fractures in other areas which are less well exposed, or less well characterized.

\section{Materials and Methods}

The initial task associated with this request involved identifying a viable field technology that would allow for the measurement of radon, specifically $\mathrm{Rn}-222$, in soil gas. Requirements of the technology were as follows:

- Field rugged

- Simplistic, passive sampling design

- Ease of deployment (minimal resources required)

- Not susceptible to short-term fluctuations in radon emanation rates

- Inexpensive.

An extensive literature search and technology review was conducted, and the CR-39 particle track detector technology was determined to meet the project requirements. A commercial vendor was identified that provided both the CR-39 detectors as well as analysis of the detector media and reporting of the analytical results.

\section{CR-39 Detectors}

Columbia Resin \#39 (CR-39), or allyl diglycol carbonate, is a plastic polymer commonly used to manufacture lenses for eyeglasses. When used as a radiation detection medium, the CR-39 material is exposed directly to particulate radiation. In this study, the alpha particles emitted during the decay of Ra-222, are the particles being detected. These energetic particles create ion tracks across the surface of the plastic. These tracks are then enlarged through an etching process using a caustic solution such as sodium hydroxide. The tracks, easily visible through a microscope, are counted. The number of visible tracks in a given area of the CR-39 material is proportional to the concentration of Rn-222 gas that the detectors were exposed to. CR-39 detectors are commonly used throughout the United States for measurement of Rn-222 gas in homes and businesses. In this study, the concentration of Rn-222 in soil gas was the quantity of concern.

Fielding the CR-39 detectors at the Shepley's Hill site required the design and implementation of a deployment methodology that would allow for rapid deployment of numerous detectors within a week time period. It was determined that approximately 96 detectors would need to be deployed at the study location. The Rapidly Deployable CR-39 Measurement Port (Figure 2) was designed and employed for this study. (The patent process has been initiated by INL and EPA for this technology.) These measurement ports were installed along five transects at the Shepley's Hill site as shown in Figure 3.

STI Number: INL/EXT-12-27844

Revision: 0 


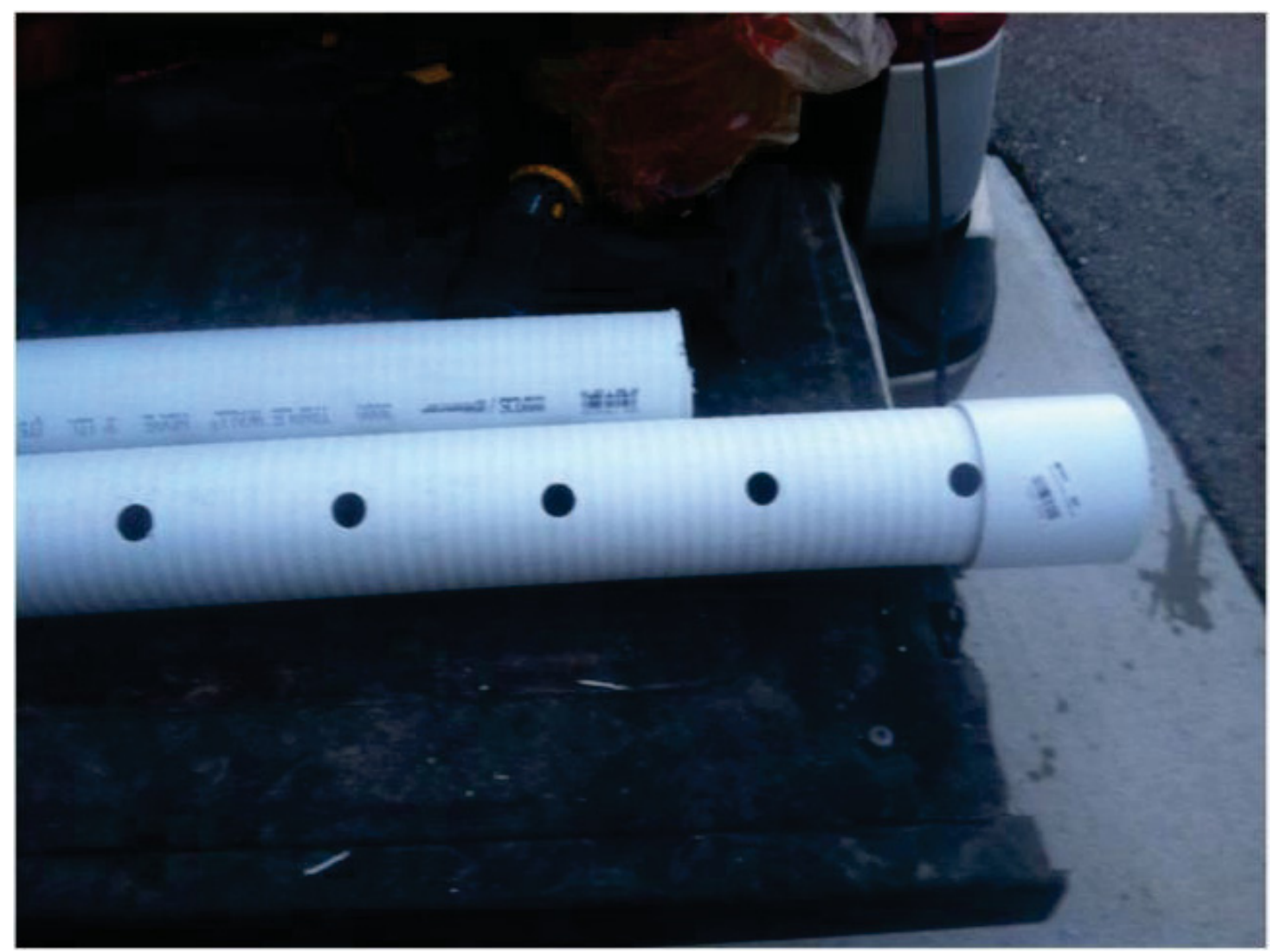

Figure 2. Rapidly deployable CR-39 measurement port.

\section{Survey and Transect Design}

The survey and transect design took advantage of extensive geological studies completed at the site (Gannett Fleming, 2012). This work identified two major bedrock fracture systems which express themselves in the surface topography as distinct linear valleys indicative of steeply dipping fracture zones within the granitic bedrock. The Disc Golf fracture zone strikes generally north-south in a series of parallel topographic ridges and valleys extending hundreds of feet in length along the western portion of the study area. The aggregate width of the zone is on the order of 300 feet. In the northeastern portion of the study area, the Nona-Shep fracture zone was identified, which strikes southeast-northwest, is expressed as a topographic valley extending hundreds of feet laterally, and has an aggregate width on the order of 200-300 feet. Major and minor interpreted fractures are located on Figure 6.

Figure 3 shows the site topography, which closely mimics the shape of the top-of-bedrock surface. Transect lines are also shown on Figure 3. Transect alignments were generally selected to intersect the major fracture systems orthogonally. Several short lines were also positioned within and parallel to the strike of the fracture sets. The southernmost transect was located in an area which was generally thought to be underlain by relatively less fractured bedrock. A general goal which also guided transect location was to bias the line locations toward areas of shallowly covered bedrock to the extent possible. A 25-foot spacing was selected between each CR-39 detector deployment location, in an attempt to balance lateral data density with project cost.

STI Number: INL/EXT-12-27844

Revision: 0 


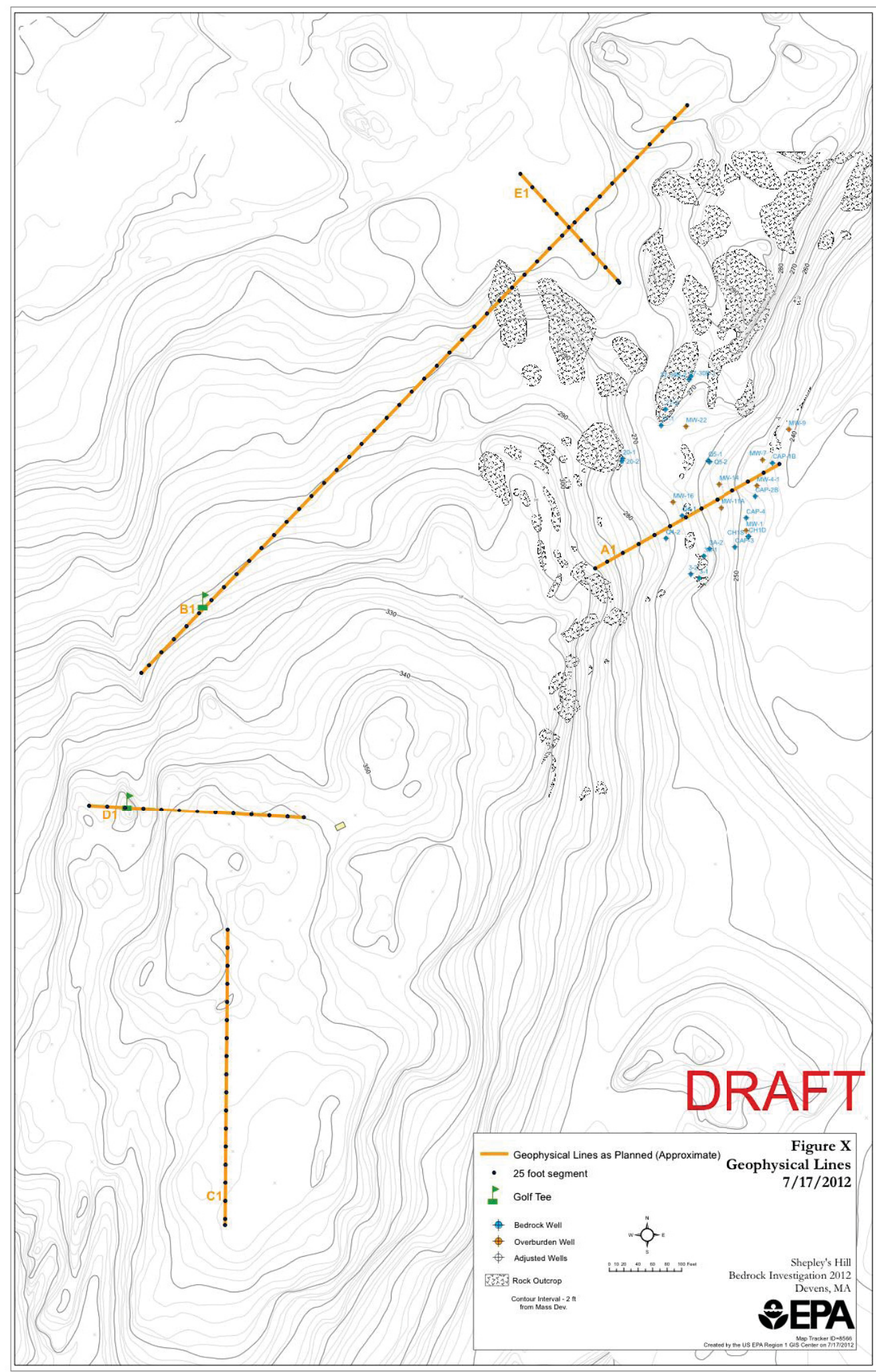

Figure 3. Transects and initial measurement port locations for radon gas study at Shepley's Hill.

STI Number: INL/EXT-12-27844

Revision: 0 
After the transect locations and measurement points along the transects were selected, the measurement probes were installed. Probe installation required the use of a hand-operated, motorized auger. At each probe location, a 4-inch diameter hole was augered into the soil to the soil-bedrock interface. The probes were placed in the ground, and the top around the probe was sealed with chip bentonite to prevent water flow down the annulus of the probe. Figure 4 shows one of the ports after emplacement, with a CR-39 detector being lowered into place. An effort was made at each location to install the detector housing to a depth just above the bedrock surface. This was achieved at the majority of locations. However, at a number of locations, primarily within the axis of the Nona-Shep fracture system, depths to bedrock were greater than the length of the portable auger, and as a result, final deployment depths were on the order of 4 to 5 feet below ground in some cases, even though topof-bedrock was not encountered. Additional installation problems occurred at locations with very shallow bedrock. In cases where bedrock was buried by less than one foot of soil, detector installation was practically difficult, and several stations were abandoned for this reason. At the end of the probe installation, a total of 92 probes had been placed along six transects. (An additional transect, Transect $F$, was added between Transects B and D.) The CR-39 detectors were deployed for a period of 21 days. The detectors were retrieved from the measurement ports, and shipped to the laboratory for analysis.

STI Number: INL/EXT-12-27844

Revision: 0 


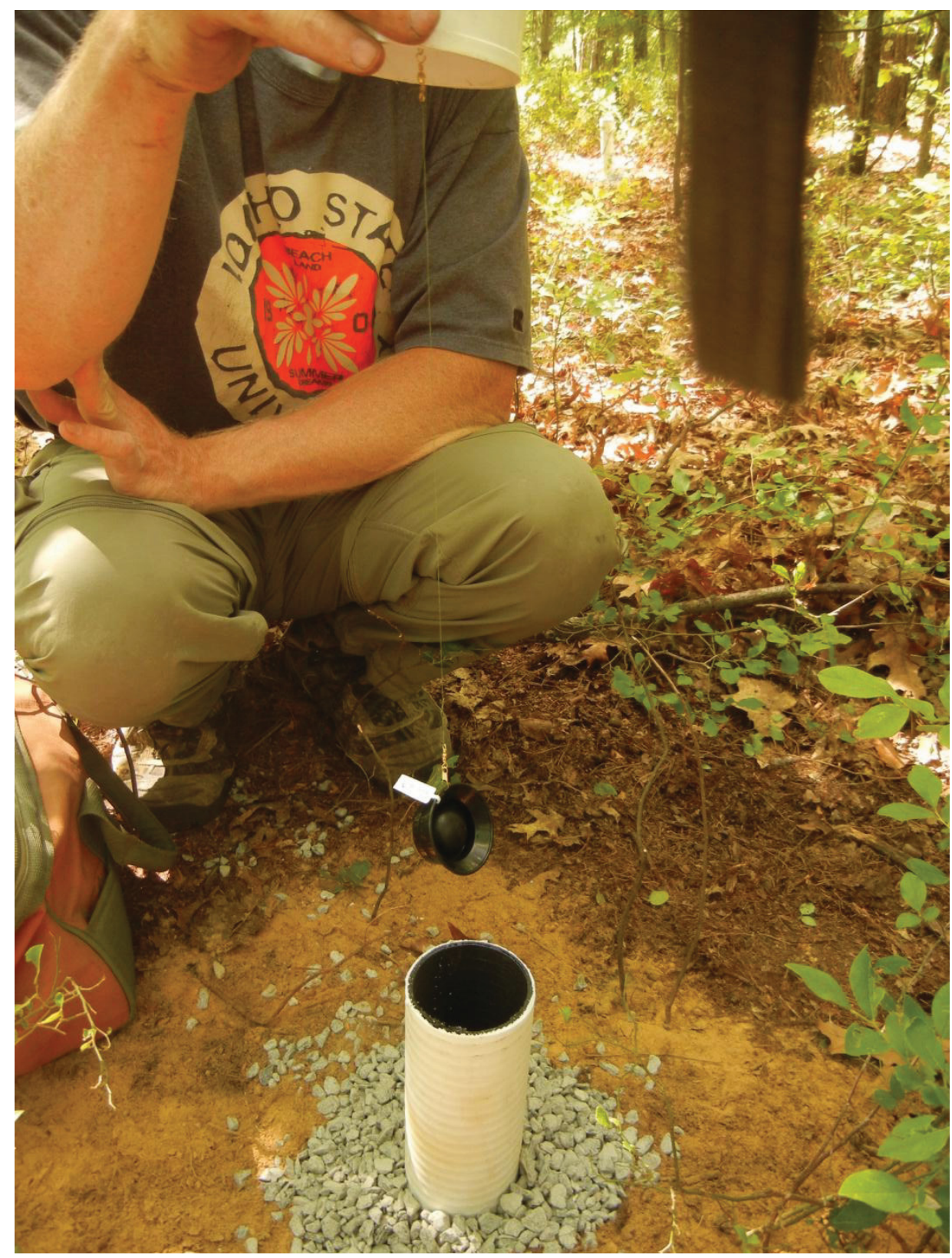

Figure 4. Installed measurement port with CR-39 detector being lowered into position.

STI Number: INL/EXT-12-27844

Revision: 0 


\section{Results and Discussion}

Analytical results were obtained for the 92 CR-39 detectors. The analytical results were reported as concentration of Rn-222 in soil gas in units of picocuries per liter (pCi/L) of soil gas. Out of the 92 detectors, six of the locations had analytical results flagged by the laboratory as "invalid" due to the reported concentration exceeding the maximum of the calibration range at $167 \mathrm{pCi} / \mathrm{L}$. Table 1 summarizes the $\mathrm{Rn}-222$ soil gas concentrations for each of the six transects.

Table 1. Rn-222 soil gas concentration data summary.

\begin{tabular}{|c|c|c|c|}
\hline \multicolumn{4}{|l|}{ Transect A } \\
\hline Number of Probes & Minimum & Maximum & Mean \\
\hline 9 & 117 & 163 & 145 \\
\hline \multicolumn{4}{|l|}{ Transect B } \\
\hline Number of Probes & Minimum & Maximum & Mean \\
\hline 51 & 6.6 & $160^{\mathrm{a}}$ & 90 \\
\hline \multicolumn{4}{|l|}{ Transect C } \\
\hline Number of Probes & Minimum & Maximum & Mean \\
\hline 8 & 30 & $141^{b}$ & 91 \\
\hline \multicolumn{4}{|l|}{ Transect D } \\
\hline Number of Probes & Minimum & Maximum & Mean \\
\hline 10 & 26 & 157 & 107 \\
\hline \multicolumn{4}{|l|}{ Transect E } \\
\hline Number of Probes & Minimum & Maximum & Mean \\
\hline 8 & 43 & 153 & 106 \\
\hline \multicolumn{4}{|l|}{ Transect F } \\
\hline Number of Probes & Minimum & Maximum & Mean \\
\hline 6 & 122 & $157^{\mathrm{C}}$ & 144 \\
\hline \multicolumn{4}{|c|}{$\begin{array}{l}\text { aTwo probe locations in Transect B had concentrations of } 167 \text { flagged as "invalid." } \\
\text { bOne probe location in Transect C had a concentration of } 167 \text { flagged as "invalid." } \\
\text { cThree probe locations in Transec F had concentrations of } 167 \text { flagged as "invalid." }\end{array}$} \\
\hline
\end{tabular}

The data in Table 1 show a wide range of Rn-222 concentrations, ranging from a low of $6.6 \mathrm{pCi} / \mathrm{L}$ in Transect B to a maximum (valid) of $163 \mathrm{pCi} / \mathrm{L}$ in Transect A. A more illustrative depiction of the data is provided by plotting the concentrations of the measured Rn-222 concentrations on a map of the study area as shown in Figure 5, and further detail is provided in Figure 6 with the locations of the known larger-scale fracture sets plotted with the Rn-222 data.

Based on these figures, there appears to be a correlation between the locations of known fractures and the higher concentrations of Rn-222. Looking at the probes in Transects B, D and F that intersect the Disc Golf fracture zone, the Rn-222 concentrations in these locations are almost exclusively greater than 100 $\mathrm{pCi} / \mathrm{L}$. Similarly, the Rn-222 concentrations from the probe locations in Transects A, B and E that intersect the Nona-Shep fracture zone are also elevated above $100 \mathrm{pCi} / \mathrm{L}$. This is in contrast with the

STI Number: INL/EXT-12-27844

Revision: 0 
probes along Transects $B$ and $C$ that do not intersect large fracture sets showing relatively low $\mathrm{Rn}-222$ concentrations (i.e. less than $100 \mathrm{pCi} / \mathrm{L}$ ).

STI Number: INL/EXT-12-27844

Revision: 0 


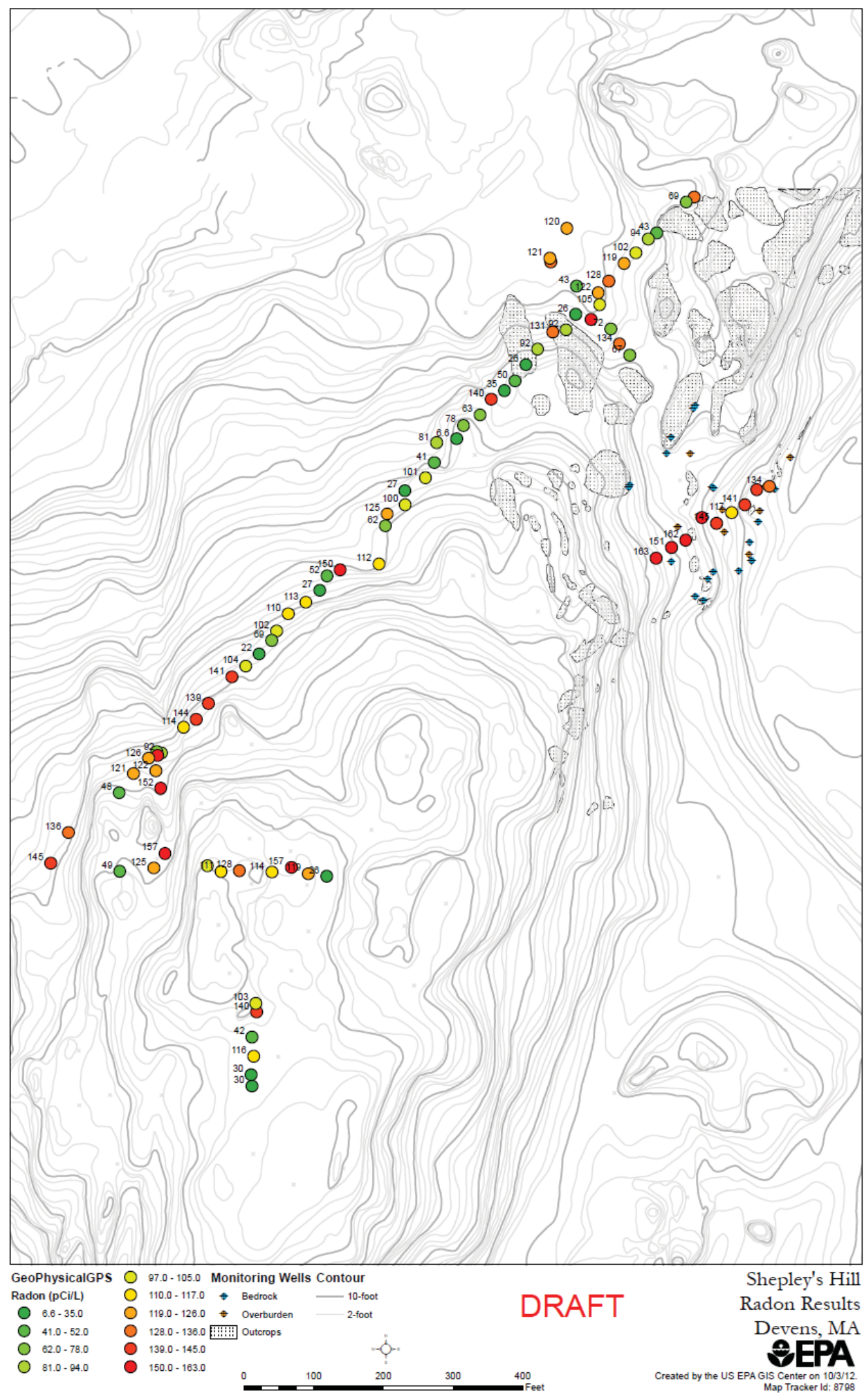

STI Number: INL/EXT-12-27844

Revision: 0 
Figure 5. Rn-222 soil gas concentrations and transect locations.

STI Number: INL/EXT-12-27844

Revision: 0 


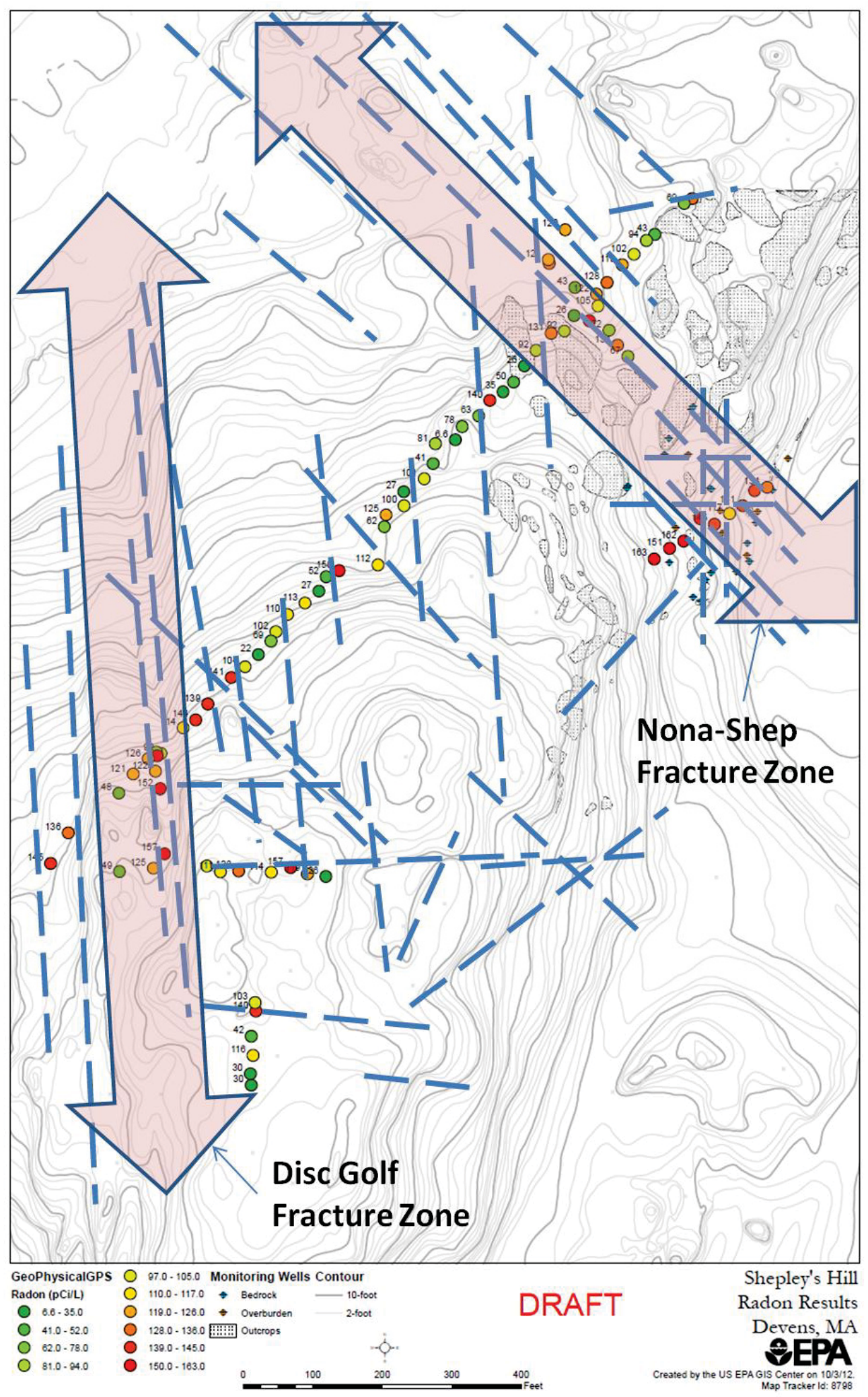

Figure 6. Rn-222 soil gas concentrations and known fracture locations at Shepley's Hill study area.

STI Number: INL/EXT-12-27844

Revision: 0 


\section{Summary and Conclusions}

This study sought to identify, test and further develop a new methodology for passively detecting the locations of fractures in buried bedrock formations. Existing CR-39 particle track detector technology was adapted to meet specific criteria which included a simple, field-rugged, passive sampling design. Additional considerations included low cost and ease of deployment. Lastly, the selected approach was chosen due to its lack of susceptibility to short-term fluctuations in radon emanation rates. A new device (Rapidly Deployable CR-39 Measurement Port) was invented, designed and employed for this study in order to adapt and deploy commercially available CR-39 detectors to the shallow subsurface environment (i.e., vadose zone).

Based on the results of this study, CR-39 particle track detector technology appears to be a viable field technology for identifying locations of bedrock fractures in shallowly buried bedrock. Results show a clear spatial correlation of elevated Rn-222 values in soil gas to known fracture zones in underlying bedrock, (previously identified by independent geologic studies). Rn-222 concentrations measured from detector locations directly above known laterally-extensive bedrock fractures were almost exclusively greater than $100 \mathrm{pCi} / \mathrm{L}$. Conversely, probes located above areas of less fractured bedrock showed relatively low Rn-222 concentrations, i.e., less than $100 \mathrm{pCi} / \mathrm{L}$.

Deployment of the technology was relatively straightforward and rapid. Total time in the field for mobilization, installation and retrieval of the 92 detectors was on the order of 5 days for a three-person crew. The only other equipment needed in addition to the detectors and the rapidly Deployable CR-39 Measurement Ports was a small quantity of coarse bentonite chips and an inexpensive power soil auger. In addition to the ease of deployment, the technology is particularly promising due to its relatively low cost. Costs for the commercially available CR-39 detectors, including analysis, were on the order of ten dollars per detector. Similarly, the rapidly Deployable CR-39 Measurement Port developed for the project was constructed from inexpensive, easily-obtained, commercially-available materials. Total costs for this approach suggest an option which is significantly less expensive than other available alternatives for subsurface bedrock fracture detection.

The results of this promising initial evaluation suggest that further research is warranted. Additional testing in a variety of geologic environments would add to the knowledge base. Similarly, improved methods and practices for implementing the technology in a variety of field settings would also help to advance the technology. Lastly, the realm of potential applications of this technology to the field of site assessment and remediation begs further exploration.

\section{Acknowledgments}

The authors would like to acknowledge several persons for assistance in completing this technology evaluation. Gordon Hamilton of the US EPA Region 1 GIS Center deserves special mention for his substantial help both in the field and in the GIS center. Michael Daly of US EPA Region 1 and Ed Gilbert of US EPA OSRTI also provided significant assistance in the field. Bryan Olson, Federal Facilities Superfund Section Chief, US EPA Region 1, and Ginny Lombardo, RPM, US EPA Region 1 provided logistical and other project support. Lastly, the authors would also like to thank Felicia Barnett, US EPA Office of Research and Development, for supporting the effort.

STI Number: INL/EXT-12-27844

Revision: 0 


\section{References}

Gannet Fleming, 2012, Shepley's Hill Bedrock Investigation, Report for US EPA Region 1.

Mazur, D., Janik, M., Łoskiewicz, J., Olko, P., Swakoń, J., 1999. Measurements of radon concentration in soil gas by Cr-39 detectors. Radiation Measurements 31, 295-300.

Swakoń, J., Kozak, K., Paszkowski, M., Gradziński, R., Łoskiewicz, J., Mazur, J., Janik, M., Bogacz, J., Horwacik, T., Olko, P., 2005. Radon concentration in soil gas around local disjunctive tectonic zones in the Krakow area. Journal of Environmental Radioactivity 78, 137-149.

İnceöz, M., Baykara, O., Aksoy, E., Doğru, M., 2006. Measurements of soil gas radon in active fault systems: A case study alone the North and East Anatolian fault systems in Turkey. Radiation Measurements 41, 349-353.

INL 2009. Surface Radiation Survey at the Shepley's Hill Remediation Site, Devens, Massachusetts. Idaho National Laboratory. INL/EXT-09-15478. September 2009.

STI Number: INL/EXT-12-27844

Revision: 0 